BENTHAM OPEN
CrossMark
Content list available at: www.benthamopen.com/TODENTJ/
DOI: $10.2174 / 1874210601711010539$

RESEARCH ARTICLE

\title{
Oral Manifestations in Pediatric Patients with Coeliac Disease - A Review Article
}

Viviana Marisa Pereira Macho ${ }^{1, *}$, Ana Sofia Coelho ${ }^{2}$, Diana Maria Veloso e Silva ${ }^{3}$ and David José Casimiro de Andrade ${ }^{4}$

${ }^{I}$ Pediatric Dentistry, Faculty of Dentistry, University of Porto, Porto, Portugal

${ }^{2}$ Faculty of Medicine, University of Coimbra, Coimbra, Portugal

${ }^{3}$ Clinical Nutrition, Faculty of Nutrition and Food Sciences, University of Porto, Porto, Portugal

${ }^{4}$ Orthodontics and Pediatric Dentistry, Faculty of Dentistry, University, of Porto, Porto, Portugal

Received: May 09, 2017

Revised: August 29, 2017

Accepted: September 19, 2017

Abstract:

Background:

Coeliac disease is a chronic enteropathy that remains a challenge for the clinician, due to its atypical manifestations and etiopathogenic complexity.

\section{Objective:}

This article intends to describe the oral characteristics of Coeliac Disease in children in order to facilitate their management in the dental office.

\section{Methods:}

A review of the literature was performed electronically in PubMed (PubMed Central, and MEDLINE) for articles published in English from 2000 to April of 2017. The article is also based on the authors' clinical experience with children with coeliac disease. The searched keywords were "coeliac disease ","oral manifestations “, "dental enamel defects", "recurrent aphthous stomatitis" and "oral aphthous ulcers".

\section{Results:}

There are some oral manifestations which are strictly related to coeliac disease: dental enamel defects, recurrent aphthous stomatitis, delayed tooth eruption, multiple caries, angular cheilitis, atrophic glossitis, dry mouth and burning tongue.

\section{Conclusion:}

The complete knowledge of the oral manifestations of coeliac disease can trigger an effective change in the quality of life of the patients with this disease.

Keywords: Coeliac disease, Oral manifestations, Dental enamel defects, Recurrent aphthous stomatitis, Oral aphthous ulcers, Gluten.

\section{INTRODUCTION}

Coeliac disease (CD) is an immune-mediated enteropathy that affects genetically susceptible subjects following exposure to gluten in the diet [1 - 3]. Gluten is a proline-rich and glutamine-rich protein present in wheat (gliadin)

\footnotetext{
* Address correspondence to this author at the Pediatric Dentistry, Faculty of Dentistry, University of Porto, Rua 31 de Janeiro ${ }^{\circ} 221^{\circ}$ andar, 4900-533 Póvoa de Varzim - Portugal; Tel: +351966537296; E-mail: vivimacho@gmail.com
} 
barley (hordein) and rye (secalin) [4 - 6]. In different parts of the world the prevalence of CD has been estimated to be approximately $0.5 \%-1 \%[4,7]$. Current research in this area enables the detection of silent forms of the disease and makes it possible to assess its real prevalence, which is higher than initially thought [2].

This disorder is characterized by typical histological jejunal lesions showing total or subtotal villous atrophy, crypt hyperplasia and lymphocyte infiltration, which results in malabsorption of most nutrients in the small intestine $[8,9]$.

CD individuals may present extraintestinal or gastrointestinal symptoms (with a typical enteropathy, characterized by a malabsorption syndrome) or none of these $[10,11]$. Atypical forms are also common and therefore often unsuspected [10,12]. Due to the wide range of clinical manifestations oral lesions should not be overlooked [1, 12, 13].

\section{METHODS}

A review of the literature was performed electronically in PubMed (PubMed Central, and MEDLINE) for articles published in English from 2000 to April of 2017. The article is also based on the authors' clinical experience with children with coeliac disease. Extensive literature survey was conducted using the key words "coeliac disease", "oral manifestations", "dental enamel defects", "recurrent aphthous stomatitis" and "oral aphthous ulcers". A qualitative text analysis was done to select relevant scientific articles on the subject under study. The initial number of selected articles based on titles and abstracts was 54 and after a full text analysis 43 articles were included in the review.

\section{RESULTS}

A large prevalence of oral manifestations in patients with coeliac disease is described by numerous authors and some of the manifestations may be considered a diagnostic clue in silent-atypical forms of CD [14]. The oral manifestations strictly related to coeliac disease are: dental enamel defects, recurrent aphthous stomatitis, delayed tooth eruption, caries, geographic tongue, angular cheilitis, atrophic glossitis, burning tongue and dry mouth [14 - 16].

\subsection{Oral Soft Tissue Lesions}

\subsubsection{Recurrent Aphthous Stomatitis}

Recurrent aphthous stomatitis (RAS) is the most common oral cavity inflammatory ulcerative condition, making its diagnosis and management a common problem in general and dental practice [17]. RAS is characterized by multiple recurrent small, round or ovoid ulcers with circumscribed margins, erythematous haloes and yellow or gray floors, typically presenting first in childhood or adolescence [17].

Though not fully understood, there are many factors associated to the etiology of RAS, including positive family history, local trauma, stress, immune changes, hormonal imbalance, food hypersensitivity and nutritional deficiencies [17 - 19]. This multifactorial disorder usually manifests itself in the non-keratinized oral mucosa and can cause considerable pain [20].

RAS is one of the most prevalent oral pathological conditions, affecting $10-20 \%$ of the general population and it's more prevalent in children with nutritional deficiencies, immunodeficiencies, malabsorption and coeliac disease $[17,18$, $21,22]$.

Some authors suggest that RAS can be considered a sign of the atypical or the silent forms of CD. Campisi et al. completed a study with a group of 269 patients (3-17 years) with coeliac disease (confirmed both serologically and histologically) and compared them with a 575 healthy individuals group [10]. Aphthous-like ulcers were more frequently found in children with coeliac disease (22.7\% vs $7.1 \%$ of controls) [10]. In the study of Procaccini et al. the prevalence of RAS was $26 \%$ in coeliac patients [23]. Bucci et al. found a prevalence of $33.3 \%$ of RAS in coeliac patients and reported that more than $1 / 3$ of the coeliac subjects suffering from RAS benefited from a gluten-free diet [15].

In the study of Bramanti et al. RAS was found in 26/50 (52\%) ascertained coeliac patients, 14/21 (66.7\%) potential coeliac patients and 4/54 (7.4\%) controls. This study also reported that RAS was more frequent in silent coeliac patients, who did not report any gastrointestinal symptoms before the diagnosis of CD [24].

This oral pathology usually occurs in the non-keratinized oral mucosa and affects the feeding, the speech and the swallowing as well as the tooth brushing. It also causes emotional instability because it can be the reason of 
considerable pain [20].

\subsubsection{Geographic Tongue}

The geographic tongue is a chronic, inflammatory and immuno-mediated oral lesion with an unknown etiology [25]. Atrophy of the filiform papillae leaves an erythematous area with a white, yellow or grey elevated peripheral zone and irregular jagged pattern of the tongue [25]. This manifestation may occur secondarily to an iron, folic acid or vitamin B12 deficiency, resulting from intestinal malabsorption [26]. In the study of Bramanti et al. the geographic tongue was found in 5/50 (10\%) ascertained coeliac patients, 4/21 (19\%) potential coeliac patients, and 2/54 (3.7\%) control subjects [24]. Cigic et al. found that 9 (15\%) patients with geographic tongue were positive for IgA tTG and in those patients histological changes consistent with $\mathrm{CD}$ were confirmed by duodenal biopsy. Only two of the patients reported gastrointestinal symptoms [25].

\subsubsection{Atrophic Glossitis}

Atrophic glossitis is an inflammatory disorder of the tongue mucosa. The tongue becomes smooth and with a shiny appearance with a red or pink background [27]. The smooth appearance is linked to the atrophy of filiform papillae that causes the development of circinate erythematous ulcer-like lesions on the dorsum and on the lateral border of the tongue [27]. The patients referred chewing, swallowing and/or speaking difficulties. This condition was noticed in the study of Bramanti et al. in 7/50 (14\%) ascertained coeliac patients and 5/21 (23.8\%) potential coeliac patients versus $1 / 54(1.85 \%)$ controls [24].

\subsubsection{Angular Cheilitis}

Angular cheilitis is a common condition characterized by erythema, ulceration, diffuse redness with an eroded area and crusting in the corners of the mouth [24]. This extra oral condition was recorded in the study of Bramanti et al. in $3 / 50(6 \%)$ ascertained coeliac patients and $2 / 21(9.5 \%)$ potential coeliac patients versus $2 / 54(3.7 \%)$ patients of the control group [24].

\subsubsection{Burning Tongue}

Burning tongue is characterized by oral tingling sensations, numbness and even burning sensation and severe pain, associated with objective signs of erythema and edema of papillae on the tip of the tongue not linked to any type of physical trauma [24]. It was registered in the study of Bramanti et al. in 7/50 (14\%) ascertained coeliac patients, $2 / 21$ $(9.5 \%)$ potential coeliac patients and $3 / 54$ (5.55\%) control patients [24].

\subsection{Oral Hard Tissue Lesions}

\subsubsection{Dental Enamel Defects}

Impairment of dental crowns mineralization may occur in numerous systemic diseases but the defects found in coeliac patients are highly specific [28 - 30]. Dental enamel defects are mainly characterized by pitting, grooving and sometimes complete loss of enamel [24,31]. These specific enamel defects have to be symmetrically and chronologically detectable in all four sections of the dentition [30, 32]. Other enamel defects (discolorations, hypoplasia or opacities) that are not symmetrical nor chronological and that are not present in the same teeth of both hemiarches are considered unspecific. Dental enamel structural defects may be diverse and may contain hypoplasia (functional disturbances) as well as hypomineralization (qualitative disturbances) [33]. For the purpose of the assessment of those changes, Aine et al. (Table 1) classified the specific enamel defects in grades I-IV according to the severity of their clinical aspect [24, 30 - 32].

The etiology of dental enamel defects in coeliac patients is not precisely clarified [34]. Some authors refer that the enamel defects could be related to hipocalcemia: the low serum levels of calcium resulting from intestinal malabsorption are decisive for the origin of enamel defects [35]. However, in a study by Wierink et al., the number of enamel defects was higher in CD patients compared to the control group which also had intestinal malabsorption [35]. Another study mentioned that an autoimmune response against ameloblasts may be at the etiological origin of enamel defects in coeliac patients [35]. Others referred a particular genetic condition that leads to a specific immune response to gluten. Coeliac patients with HLA-DR3 genotype presented a higher risk of enamel lesions, pointing to a genetic etiology [35]. 
Malnutrition and vitamins D and A deficiency are also associated to enamel hypoplasia [36]. It is still unclear whether the oral lesions represent a direct manifestation of $\mathrm{CD}$ or whether they occur as a result of the indirect effects of malabsorption [36].

Table 1. Classification of dental enamel defects in coeliac disease according to Aine [24, 30 - 32$]$.

\begin{tabular}{|c|c|}
\hline Grade 0 & No Defects. \\
\hline Grade I & $\begin{array}{c}\text { Defect in enamel color. Single or multiple cream, yellow or brown opacities (marks) with clear or hazed boundary, part of the dental } \\
\text { enamel may lack transparency. }\end{array}$ \\
\hline Grade II & Slight structural enamel defects, rough surface with horizontal groves or pits, distortion of enamel color and transparency. \\
\hline Grade III & $\begin{array}{l}\text { Evident structural defects. A part or the entire surface of enamel rough and filled with deep horizontal grooves that vary in width or have } \\
\text { large vertical pits; large opacities of different colors or strong discolorations may appear in combination. }\end{array}$ \\
\hline Grade IV & $\begin{array}{l}\text { Severe structural defects. The shape of the tooth changed. The tips of cusps are sharp-pointed and/or the incisal edges are unevenly thinned } \\
\text { and rough. The thinning of the enamel material is easily detectable and the lesion may be strongly discolored. }\end{array}$ \\
\hline
\end{tabular}

Enamel defects could be a major sign of CD [23, 29, 34]. The overall prevalence of this oral manifestation ranges from $9.52 \%$ to $95.94 \%$ [14, 29, 34]. Avşar and Kalayci reported that enamel defects were significantly higher in CD patients $(42.2 \%)$ than in the control group $(9.4 \%)$ [29, 34]. In the study of Wierink et al. enamel defects were found in $55 \%$ of the CD patients and in $18 \%$ of the control group [34, 35]. Campisi et al. observed specific dental enamel lesions in $60 \%$ of the patients with coeliac disease and only in $15 \%$ of the control group [10, 34]. A study of Cantekin et al. also reported a higher prevalence of enamel defects (48\%) in CD patients compared to the control group (16\%). The enamel defects in that study were generally symmetrical and mostly seen in anterior teeth [34]. In the study of Bramanti et al. the prevalence of specific enamel defects was $48 \%$ in ascertained coeliac and $19 \%$ in potential coeliac versus $0 \%$ in controls [24]. Costacurta et al. demonstrated that enamel hypoplasia was more prevalent in coeliac patients (33\%) compared to healthy subjects $(11 \%)$. The authors mentioned that the enamel defects found in coeliac individuals were more specific that the ones found in the control group; in fact many authors reported a symmetrical distribution, a chronologic coherence and the involvement of all dental hemi-arches [37]. A study by Bossu et al. reported that the enamel of CD patients was more fragile than the enamel of non-coeliac patients. The authors also described that the enamel prisms of the coeliac patients were short and highly hypomineralised, with an irregular distribution and with a smaller quantity of interprismatic substance when compared to that of non-coeliac patients [31].

The North American Society for Pediatric Gastroenterology, Hepatology, and Nutrition (NASPGHAN) included the presence of specific dental enamel defects as a risk factor for CD [4, 36].

\subsubsection{Dental Caries}

Concerning dental caries there is some controversy.

Some studies reported that the prevalence of caries in CD was lower comparing to healthy subjects. A possible explanation for these results is the need for a carefully controlled diet. These patients maintain a rigid gluten free diet, which is a protein that can be found in several cariogenic foods, such as oatmeal, flours and breads, among others $[30,32,38]$.

However, some authors reported a higher prevalence of caries in these patients. Hypoplasic enamel, changes in salivary composition and a low salivary flow rate are described and could constitute risk factors for dental caries [37]. The decrease of the salivary flow rate is related to the active phase of the disease and in concomitance with gluten-free diet. This decrease can cause dryness of the oral cavity and a burning tongue sensation, which can increase the risk for oral infections, including dental caries. Some authors have found that in a gluten-free diet regime coeliac patients had a low salivary concentration of amylase, $\operatorname{IgA}$ and $\operatorname{IgM}$, a smaller volume of stimulated saliva, a lower buffering capacity and a lower calcium / phosphate ratio, which can influence the prevalence of dental caries [22, 38 - 40].

\subsubsection{Delayed Tooth Eruption}

Prolonged malnutrition can have irreversible effects on tooth eruption. Since children with DC are often subject to weight loss and have lower somatic growth compared to healthy children, it is hypothesized that the development of the teeth is also subject to a delay [41].

Campisi et al. and Costacurta et al. observed a significantly more frequent occurrence of these disturbances in children with coeliac disease when compared to healthy children [10,41]. According to Campisi et al., delayed dental eruption may, similarly to the failure to thrive, be a signal of malnutrition and requires diagnostics toward gluten 
intolerance [10]. However, Mina et al. did not observe an association between the time of tooth eruption and coeliac disease [22].

The intra-oral observation of these patients presents as a cheap, quick and non-invasive procedure and the knowledge of coeliac disease's oral manifestations may allow for the diagnosis of patients affected by silent-atypical forms of CD [37, 42]. Therefore, the oral manifestations can be the only presenting signs or symptoms in patients with undiagnosed CD [43]. When CD is suspected, dental practitioners should communicate with the physician so a screening for coeliac disease can be scheduled [37, 42, 43].

After diagnosis, all coeliac patients should be included in a preventive dental program aiming to provide professional oral hygiene, pits and fissures sealing, fluoride topical application and treatment of dental caries and fractures of hypoplasic enamel [37].

\section{CONCLUSION}

Dental and oral manifestations such as dental enamel defects and recurrent aphthous ulcers are well-recognized manifestations of CD. Meticulous examination of the oral cavity with particular attention to these signs may contribute to an early diagnosis of coeliac disease.

The complete knowledge of the coeliac disease oral manifestations can trigger an effective change in the quality of life of these patients, propitiated by a joint and complementary work of a multidisciplinary team.

\section{ETHICS APPROVAL AND CONSENT TO PARTICIPATE}

Not applicable.

\section{HUMAN AND ANIMAL RIGHTS}

No Animals/Humans were used for studies that are base of this research.

\section{CONSENT FOR PUBLICATION}

Not applicable.

\section{CONFLICT OF INTEREST}

The authors declare no conflict of interest, financial or otherwise.

\section{ACKNOWLEDGEMENTS}

Viviana Macho was responsible for the conception and design;

Viviana Macho and Ana Coelho were responsible for the data collection and manuscript redaction;

David Andrade and Diana e Silva were responsible for the critical revision of its intellectual contents and final approval of the version to be published.

\section{REFERENCES}

[1] Kneepkens CM, von Blomberg BM. Clinical practice : Coeliac disease. Eur J Pediatr 2012; 171(7): 1011-21 [http://dx.doi.org/10.1007/s00431-012-1714-8] [PMID: 22422192]

[2] Husby S, Koletzko S, Korponay-Szabó IR, et al. ESPGHAN working group on coeliac disease diagnosis; ESPGHAN Gastroenterology Committee; European Society for Pediatric Gastroenterology, Hepatology, and Nutrition. European Society for Pediatric Gastroenterology, Hepatology, and Nutrition guidelines for the diagnosis of coeliac disease. J Pediatr Gastroenterol Nutr 2012; 54(1): 136-60. [http://dx.doi.org/10.1097/MPG.0b013e31821a23d0] [PMID: 22197856]

[3] Bai JC, Fried M, Corazza GR, et al. World Gastroenterology Organization. World Gastroenterology Organisation global guidelines on celiac disease. J Clin Gastroenterol 2013; 47(2): 121-6. [http://dx.doi.org/10.1097/MCG.0b013e31827a6f83] [PMID: 23314668]

[4] Hill ID, Dirks MH, Liptak GS, et al. North American Society for pediatric gastroenterology, hepatology and nutrition. guideline for the diagnosis and treatment of celiac disease in children: Recommendations of the North American Society for Pediatric Gastroenterology, Hepatology and Nutrition. J Pediatr Gastroenterol Nutr 2005; 40(1): 1-19. [http://dx.doi.org/10.1097/00005176-200501000-00001] [PMID: 15625418]

[5] Szajewska H, Shamir R, Mearin L, et al. Gluten introduction and the risk of coeliac disease: A position paper by the european society for pediatric gastroenterology, hepatology, and nutrition. J Pediatr Gastroenterol Nutr 2016; 62(3): 507-13. 
[http://dx.doi.org/10.1097/MPG.0000000000001105] [PMID: 26815017]

[6] Di Sabatino A, Corazza GR. Coeliac disease. Lancet 2009; 373(9673): 1480-93. [http://dx.doi.org/10.1016/S0140-6736(09)60254-3] [PMID: 19394538]

[7] Elli L, Branchi F, Tomba C, et al. Diagnosis of gluten related disorders: Celiac disease, wheat allergy and non-celiac gluten sensitivity. World J Gastroenterol 2015; 21(23): 7110-9. [http://dx.doi.org/10.3748/wjg.v21.i23.7110] [PMID: 26109797]

[8] Tian N, Faller L, Leffler DA, et al. Salivary gluten degradation and oral microbial profiles in healthy individuals and celiac disease patients. Appl Environ Microbiol 2017; 83(6): e03330-16.

[http://dx.doi.org/10.1128/AEM.03330-16] [PMID: 28087531]

[9] Fasano A, Catassi C. Current approaches to diagnosis and treatment of celiac disease: An evolving spectrum. Gastroenterology 2001; 120(3): 636-51. [http://dx.doi.org/10.1053/gast.2001.22123] [PMID: 11179241]

[10] Campisi G, Di Liberto C, Carroccio A, et al. Coeliac disease: Oral ulcer prevalence, assessment of risk and association with gluten-free diet in children. Dig Liver Dis 2008; 40(2): 104-7.

[http://dx.doi.org/10.1016/j.dld.2007.10.009] [PMID: 18063428]

[11] Torres MI, López Casado MA, Ríos A. New aspects in celiac disease. World J Gastroenterol 2007; 13(8): 1156-61. [http://dx.doi.org/10.3748/wjg.v13.i8.1156] [PMID: 17451193]

[12] Harris LA, Park JY, Voltaggio L, Lam-Himlin D. Celiac disease: Clinical, endoscopic, and histopathologic review. Gastrointest Endosc 2012; 76(3): 625-40.

[http://dx.doi.org/10.1016/j.gie.2012.04.473] [PMID: 22898420]

[13] Shteyer E, Berson T, Lachmanovitz O, et al. Oral health status and salivary properties in relation to gluten-free diet in children with celiac disease. J Pediatr Gastroenterol Nutr 2013; 57(1): 49-52. [http://dx.doi.org/10.1097/MPG.0b013e31828b3705] [PMID: 23403442]

[14] Pastore L, Carroccio A, Compilato D, Panzarella V, Serpico R, Lo Muzio L. Oral manifestations of celiac disease. J Clin Gastroenterol 2008; 42(3): 224-32. [PMID: 18223505]

[15] Bucci P, Carile F, Sangianantoni A, D’Angiò F, Santarelli A, Lo Muzio L. Oral aphthous ulcers and dental enamel defects in children with coeliac disease. Acta Paediatr 2006; 95(2): 203-7.

[http://dx.doi.org/10.1080/08035250500355022] [PMID: 16449028]

[16] Lähteenoja H, Toivanen A, Viander M, et al. Oral mucosal changes in coeliac patients on a gluten-free diet. Eur J Oral Sci 1998; 106(5): 899-906. [http://dx.doi.org/10.1046/j.0909-8836.1998.eos106501.x] [PMID: 9786318]

[17] Chavan M, Jain H, Diwan N, Khedkar S, Shete A, Durkar S. Recurrent aphthous stomatitis: A review. J Oral Pathol Med 2012; 41(8): 577-83. [http://dx.doi.org/10.1111/j.1600-0714.2012.01134.x] [PMID: 22413800]

[18] Kozlak ST, Walsh SJ, Lalla RV. Reduced dietary intake of vitamin B12 and folate in patients with recurrent aphthous stomatitis. J Oral Pathol Med 2010; 39(5): 420-3. [PMID: 20141576]

[19] Baccaglini L, Lalla RV, Bruce AJ, et al. Urban legends: Recurrent aphthous stomatitis. Oral Dis 2011; 17(8): 755-70. [http://dx.doi.org/10.1111/j.1601-0825.2011.01840.x] [PMID: 21812866]

[20] Krisdapong S, Sheiham A, Tsakos G. Impacts of recurrent aphthous stomatitis on quality of life of 12 and 15 years old Thai children. Qual Life Res 2012; 21(1): 71-6. [http://dx.doi.org/10.1007/s11136-011-9925-4] [PMID: 21574018]

[21] Majorana A, Bardellini E, Flocchini P, Amadori F, Conti G, Campus G. Oral mucosal lesions in children from 0 to 12 years old: Ten years' experience. Oral Surg Oral Med Oral Pathol Oral Radiol Endod 2010; 110(1): e13-8. [http://dx.doi.org/10.1016/j.tripleo.2010.02.025] [PMID: 20452255]

[22] Mina S, Riga C, Azcurra AI, Brunotto M. Oral ecosystem alterations in celiac children: A follow-up study. Arch Oral Biol 2012; 57(2): $154-60$. [http://dx.doi.org/10.1016/j.archoralbio.2011.08.017] [PMID: 21920498]

[23] Procaccini M, Campisi G, Bufo P, et al. Lack of association between celiac disease and dental enamel hypoplasia in a case-control study from an Italian central region. Head Face Med 2007; $3: 25$. [http://dx.doi.org/10.1186/1746-160X-3-25] [PMID: 17537244]

[24] Bramanti E, Cicciu M, Matacena G, Costa S, Magazzu G. Clinical evaluation of specific oral manifestations in pediatric patients with ascertained vs potential coeliac disease: A Cross-Sectional Study. Gastroent Res Pract 2014.

[25] Cigic L, Galic T, Kero D, et al. The prevalence of celiac disease in patients with geographic tongue. J Oral Pathol Med 2016; 45(10): 791-6. [http://dx.doi.org/10.1111/jop.12450] [PMID: 27131886]

[26] da Silva PC, de Almeida PdelV, Machado MA, et al. Oral manifestations of celiac disease. A case report and review of the literature. Med Oral Patol Oral Cir Bucal 2008; 13(9): E559-62. 
[PMID: 18758399]

[27] Erriu M, Canargiu F, Orrù G, Garau V, Montaldo C. Idiopathic atrophic glossitis as the only clinical sign for celiac disease diagnosis: A case report. J Med Case Reports 2012; 6: 185.

[http://dx.doi.org/10.1186/1752-1947-6-185] [PMID: 22762365]

[28] Trotta L, Biagi F, Bianchi PI, et al. Dental enamel defects in adult coeliac disease: Prevalence and correlation with symptoms and age at diagnosis. Eur J Intern Med 2013; 24(8): 832-4.

[http://dx.doi.org/10.1016/j.ejim.2013.03.007] [PMID: 23571066]

[29] Avşar A, Kalayci AG. The presence and distribution of dental enamel defects and caries in children with celiac disease. Turk J Pediatr 2008; 50(1): 45-50. [PMID: 18365591]

[30] de Carvalho FK, de Queiroz AM, Bezerra da Silva RA, et al. Oral aspects in celiac disease children: Clinical and dental enamel chemical evaluation. Oral Surg Oral Med Oral Pathol Oral Radiol 2015; 119(6): 636-43.

[http://dx.doi.org/10.1016/j.oooo.2015.02.483] [PMID: 25840513]

[31] Bossù M, Bartoli A, Orsini G, Luppino E, Polimeni A. Enamel hypoplasia in coeliac children: A potential clinical marker of early diagnosis. Eur J Paediatr Dent 2007; 8(1): 31-7. [PMID: 17359212]

[32] Krzywicka B, Herman K, Kowalczyk-Zając M, Pytrus T. Celiac disease and its impact on the oral health status - review of the literature. Adv Clin Exp Med 2014; 23(5): 675-81. [http://dx.doi.org/10.17219/acem/37212] [PMID: 25491679]

[33] Muñoz F, Del Río N, Sóñora C, Tiscornia I, Marco A, Hernández A. Enamel defects associated with coeliac disease: Putative role of antibodies against gliadin in pathogenesis. Eur J Oral Sci 2012; 120(2): 104-12. [http://dx.doi.org/10.1111/j.1600-0722.2012.00949.x] [PMID: 22409216]

[34] Cantekin K, Arslan D, Delikan E. Presence and distribution of dental enamel defects, recurrent aphthous lesions and dental caries in children with celiac disease. Pak J Med Sci 2015; 31(3): 606-9. [PMID: 26150853]

[35] Wierink CD, van Diermen DE, Aartman IH, Heymans HS. Dental enamel defects in children with coeliac disease. Int J Paediatr Dent 2007; 17(3): 163-8. [http://dx.doi.org/10.1111/j.1365-263X.2006.00816.x] [PMID: 17397459]

[36] El-Hodhod MA, El-Agouza IA, Abdel-Al H, Kabil NS, Bayomi KA. Screening for celiac disease in children with dental enamel defects. 2012. [http://dx.doi.org/10.5402/2012/763783]

[37] Costacurta M, Maturo P, Bartolino M, Docimo R. Oral manifestations of coeliac disease: A clinical-statistic study. Oral Implantol (Rome) 2010; 3(1): 12-9. [PMID: 23285376]

[38] Acar S, Yetkıner AA, Ersın N, Oncag O, Aydogdu S, Arıkan C. Oral findings and salivary parameters in children with celiac disease: A preliminary study. Med Princ Pract 2012; 21(2): 129-33. [http://dx.doi.org/10.1159/000331794] [PMID: 22024774]

[39] Lenander-Lumikari M, Ihalin R, Lähteenoja H. Changes in whole saliva in patients with coeliac disease. Arch Oral Biol 2000; 45(5): $347-54$. [http://dx.doi.org/10.1016/S0003-9969(00)00008-X] [PMID: 10739855]

[40] Mina SS, Azcurra AI, Dorronsoro S, Brunotto MN. Alterations of the oral ecosystem in children with celiac disease. Acta Odontol Latinoam 2008; 21(2): 121-6.

[PMID: 19177847]

[41] Condò R, Costacurta M, Maturo P, Docimo R. The dental age in the child with coeliac disease. Eur J Paediatr Dent 2011; 12(3): 184-8. [PMID: 22077688]

[42] Cheng J, Malahias T, Brar P, Minaya MT, Green PH. The association between celiac disease, dental enamel defects, and aphthous ulcers in a United States cohort. J Clin Gastroenterol 2010; 44(3): 191-4. [http://dx.doi.org/10.1097/MCG.0b013e3181ac9942] [PMID: 19687752]

[43] Rashid M, Zarkadas M, Anca A, Limeback H. Oral manifestations of celiac disease: A clinical guide for dentists. J Can Dent Assoc 2011; 77: b39.

[PMID: 21507289]

\section{(C) 2017 Macho et al.}

This is an open access article distributed under the terms of the Creative Commons Attribution 4.0 International Public License (CC-BY 4.0), a copy of which is available at: https://creativecommons.org/licenses/by/4.0/legalcode. This license permits unrestricted use, distribution, and reproduction in any medium, provided the original author and source are credited. 